УДК 78.01+78.087.1/786.2

\author{
Диана Павловна Гульцова, \\ соискатель Одесской национальной \\ музыкальной академии имени А. В. Неждановой

\section{«ТРАНСЦЕНДЕНТНЫЕ ЭТЮДЫ» Ф. ЛИСТА И С. М. ЛЯПУНОВА В РУСЛЕ ФИЛОСОФСКИХ И ЖАНРОВО-СТИЛЕВЫХ ИСКАНИЙ РОМАНТИЗМА}

Цель статьи. Статья посвящена анализу жанрово-стилевой специфики «Трансиендентных этюдов» Ф. Листа и С. М. Ляпунова, рассматриваемых в русле философско-эстетических исканий эпохи романтизма. Научная новизна. Трансиендентность названных сочинений очевидна не только в их предельно возросшем техническо-исполнительском мастерстве, но и в максимальном расширении типологии этюда, охватывающей как инструктивную риторическую сторону данного жанра, так и образно-смысловые «коды» романтического искусства в целом. Выводы. Обозначенные качества фортепианного творчества С. М. Ляпунова наиболее полно сконцентрированы в его «12-ти этюдах», которые были задуманы как своеобразное продолжение аналогичного листовского цикла.

Ключевые слова: этюд, романтизм, «трансиендентный этюд», трансиендентное в культуре романтизма, виртуоз, виртуозность.

Gultsova Diana, The Odessa National A. V. Nezhdanova Academy of Music, applicant of the department of theoretical and applied culturology

"Transcendental Etudes» by Franz Liszt and Sergei Lyapunov in line with the philosophy and genre-style romanticism searches

Purpose of Research. This article analyzes the specificity of genre-style «Transcendental Etudes» Franz Liszt and Sergei Lyapunov considered in line with the philosophical and aesthetic pursuit of the Romantic era. Scientific novelty. The transcendence of these works is evident not only in their maximum increased technical-performing skills, but also in maximizing typology scene, encompassing both instructional rhetorical side of the genre, as well as figurative sense «codes» of romantic art in general. Conclusions. The designated qualities of S. Lyapunov's piano creativity are most fully concentrated in his «12 sketches», which were conceived as a kind of continuation of a similar leaf cycle.

Keywords: etude, romanticism, "Transcendental Etudes» in a transcendent cultural romanticism, a virtuoso, virtuosity. 
Гульцова Діана Павлівна, здобувач Одеської національної музичної академії імені А. В. Нежданової

«Трансцендентні етюди» Ф. Ліста та С. М. Ляпунова у руслі філософських та жанрово-стильових пошуків романтизму

Мета статті. Стаття присвячена аналізу жанрово-стильової специфіки «Трансиендентних етюдів» Ф. Ліста та С. М. Ляпунова, що розглядаються в руслі філософсько-естетичних пошуків епохи романтизму. Наукова новизна. Трансцендентність названих творів є очевидною не тільки в їх граничній техніко-виконавській майстерності, але й у максимальному розширенні типології етюду, що охоплює як інструктивний риторичний бік цього жанру, так і образно-змістовні «коди» романтичного мистецтва в цілому. Висновки. Окреслені якості фортепіанної творчості С. М. Ляпунова найбільш повно сконцентровані в його «12-ти етюдах, які були задумані як своєрідне продовження аналогічного листовського ииклу.

Ключові слова: етюд, романтизм, «трансцендентний етюд», трансцендентне в культурі романтизму, віртуоз, віртуозність.

Актуальность. Обобщая сущность феномена романтизма, Л. Уланд в свое время определял искусство этой эпохи как «мистическое проявление... духа в образе ...вторжение мирового духа... очеловечивание Божественного, предчувствие бесконечного в видимом и воображаемом» [цит. по: 16, 84]. Идеалистические порывы в сферу высоких проявлений духовного начала, характеризующие идейно-эстетические и философские позиции романтиков, можно рассматривать как своеобразную реакцию на скептицизм, рационализм, рассудочность предшествующей эпохи Просвещения. Фиксируя внимание на доминантной роли христианского фактора в культуре романтизма, В. В. Медушевский писал следующее: «Как все великие стили, романтизм поклонялся тому, чему только и можно поклоняться: Божественной красоте, преобразующей мир и души людей... Одуховление сердца богочеловеческого «я» - содержание романтической музыки, питающееся жизненным опытом, но озаренное нездешним светом» $[14,62]$.

Сказанное во многом определяет специфику культурной идеи западноевропейского романтизма, для которого произведение искусства так или иначе несет в себе символический смысл откровения, далеко выходящего за пределы непосредственно представленного в нем образа, а фигура художника-творца, соответственно, обретает особую значимость как «властителя душ», пророка своего времени. «Поэты, - как писал П. Б. Шелли в «Защите поэзии», - жрецы не- 
постижимого вдохновения; зеркала, отражающие исполинские тени, которые грядущее отбрасывают в сегодняшний день, трубы которых зовут в бой и не слышат своего зова. Поэты - это непризнанные законодатели мира» $[18,434]$. Суммируя духовно-философские искания романтиков в широком спектре художественных проявлений культуры этой эпохи, Н. А. Бердяев уже в начале XX ст. констатировал: «Романтизм не хочет имманентной замкнутости и завершенности, он жаждет трансцендентного прорыва в бесконечность» [3, 347-348].

Приведенные высказывания, таким образом, свидетельствуют о существенной роли трансцендентного фактора в романтической картине мира и мировоззрении ее репрезентантов, что особенно очевидно проявилось в музыкальном искусстве данной эпохи. Именно музыка, признаваемая романтиками высшим из искусств, способным к наибольшей степени абстрагирования, позволяет «выяснить формы сплетения жизни и духа» (Л. Клагес), а также рассматривать данный феномен с точки зрения «исполинского интеграла, соединяющего небо и землю» (Х. Дрейер) [2].

Цель статьи. Статья посвящена анализу жанрово-стилевой специфики «Трансцендентных этюдов» Ф. Листа и С. М. Ляпунова, рассматриваемых в русле философско-эстетических исканий эпохи романтизма. Научная новизна. Трансцендентность названных сочинений очевидна не только в их предельно возросшем техническоисполнительском мастерстве, но и в максимальном расширении типологии этюда, охватывающей как инструктивную риторическую сторону данного жанра, так и образно-смысловые «коды» романтического искусства в целом.

В этом плане творческая фигура Ф. Листа и его последователей весьма показательна, поскольку она олицетворяла собой одного из величайших «трансцендентных гениев» в истории искусства XIX века. Столь ярко выраженное стремление данного автора перейти границы «Дозволенного» в искусстве характеризует не только его философские, эстетические взгляды, но и его деятельность как композитора, пианиста-виртуоза, педагога, критика, мыслителя своей эпохи. Малоисследованность данного аспекта творчества Ф. Листа, оказавшего, тем не менее, существенное воздействие и на последующие поколения европейских музыкантов (в том числе и на С. М. Ляпунова), определяет актуальность темы представленной статьи. Ее предмет ориентирован на выявление специфики интерпретации трансцендентного фактора в фортепианном творчестве Ф. Листа и наследника 
его традиций в русской музыке рубежа XIX-XX ст. С. М. Ляпунова на примере фортепианных циклов «12 трансцендентных этюдов», представленных в творчестве названных авторов. Рассмотрение данной проблематики диктует необходимость краткого обзора не только этимологии феномена трансцендентного, но и его философско-эстетической разработки в предлистовскую и листовскую эпохи.

Изложение основного материала. Слово «трансцендентный», согласно этимологии своего латинского первоисточника (transcendentis, transcendes), буквально обозначает «выходящий за пределы», «перешагивающий», «находящийся за пределами непосредственного опыта». В энциклопедических изданиях термин «трансцендентный» имеет широкую сферу применения - в христианской теологии, философии, а также и в математике. Будучи востребованным в различные исторические эпохи, он, тем не менее, сохранял свое исходное значение фиксации качеств, выходящих в процессе их познания за пределы возможного эмпирического опыта индивида [см.: 17, 579]. В диссертации И. М. Лаврухиной «трансцендентное» определяется как «сфера абсолютной потенциальности, не актуализированная в деятельности человека в данный момент времени и не выразимая в его опыте в силу принципиальной неадекватности этой сферы наличным средствам освоения мира» $[12,9]$. Вместе с тем очевиден и эволюционный аспект данного понятия, корректируемый расширением системы имманентного опыта человека. Размышляя о сущности феномена «трансцендентного» в филологической и культурно-исторической традиции, В. В. Волков указывает, что в современной практике его значение отчасти нивелируется: «недоступное» оказывается для трансцендера не просто в пределах досягаемости, но становится органичной частью его (не существования, но) Бытия, его «двоемирности», здесь-и-там принадлежности» [7, 191].

Очевидно, что в подобном толковании данный термин соотносим и с культурой, базовые понятия которой апеллируют к высоким духовным ценностям, к сакральному. Согласно выводам цитированного выше исследователя, «художник как человеческий тип - едва ли не наиболее яркий трансцендер», поскольку «он устремлен за пределы внешнего - к внутреннему, от низкого - к высокому, от общего - к индивидуальному... от утилитарного - к самодостаточному, наконец, от обыденного, очевидного - к сверхъестественному, трансцендентному» [7, 191]. Обозначенные характеристики получили наиболее законченное воплощение в музыкальной творческо-исполнительской 
традиции романтизма, в частности, в «трансцендентном типе виртуозности» (Б. Б. Бородин), наиболее полно представленном в исполнительской деятельности Ф. Листа (см. ниже).

Понятие о трансцендентном, активно используемое в культурно-исторической практике романтизма, генетически восходит к базовым идеям немецкой классической философии, в частности, к учению И. Канта, для которого данное понятие сопряжено с тем, что находится за пределами познания разума и не открывается в чувственном опыте (Бог, душа, бессмертие), но постигаемо верой. Тем не менее, констатируя факт непостигаемости трансцендентного, немецкий философ постулировал устремление к нему человеческого разума, указывая следующее: «Трансцендентными я называю те основоположения, которые действительно побуждают нас разрушить все пограничные столбы и вступить на совершенно новую почву, не признающую никакой демаркации... Основоположения, устраняющие эти границы [опыта] и даже повелевающие переступить их, называются трансцендентными» [11, 338]. Данная позиция также была достаточно близка И. Г. Фихте. Абсолютное «Я» субъекта, поставленное в центр философской системы этого немецкого мыслителя, определило ее антропоцентрический характер.

Таким образом, оба философа в исследовании проблемы постижимости Абсолюта апеллировали к знанию, вере и религии. «Однако Кант пришел к выводу о непостижимости Абсолюта через знание и о доступности его вере. Фихте, напротив, утверждал о невозможности окончательного растворения в Абсолюте путем религии и о постижении Абсолюта в мире чистого знания. Мировоззрение романтизма впитало в себя идеи обоих философов и наделило проблему познаваемости новыми смыслами» [10, 95].

Сказанное в полной мере соотносимо с духовно-эстетическими позициями Новалиса, Ф. Шлегеля, Ф. В. Шеллинга, в соответствии с которыми «ничто другое не является столь достижимым для человеческого духа, как бесконечное» $[13,107]$. Способность человека к постижению Универсума и достижению Трансцендента, согласно философии романтизма, становится возможным благодаря подключению, помимо разума, иных сторон человеческой деятельности способности к творчеству, к постижению природы и истории, становящихся в определенный момент тождественными религии.

Обозначенные духовно-философские позиции романтиков оказались достаточно близкими и для Ф. Листа, интересы которого, как 
отмечалось выше, не ограничивались только творческо-исполнительской деятельностью, но простирались и в сферу философскоэстетических открытий его эпохи. Вопрос о соотношении трансцендентного фактора в культуре романтизма и творчестве Ф. Листа не стал пока предметом фундаментальных музыкально-эстетических обобщений в отечественном музыкознании. Исключением в данном случае является публикация С. Калинина [10], суммирующая некоторые аспекты данной проблематики. Однако ограниченные рамки статьи не дают возможности автору «подкрепить» их жанрово-стилевым анализом конкретных сочинений композитора. Тем не менее, согласно выводам автора, «в контексте эстетико-философской системы Листа понимание трансцендентного синтезировало значения, выработанные в области европейского философского и художественного знания. Кроме того, при проекции философского понятия на художественное творчество, при взаимодействии с принципами собственно музыкального искусства возник ряд новых смыслов». Обобщая стилевые и исполнительские аспекты многообразного наследия композитора, С. Калинин приходит к выводу о том, что «тяготение к трансцендентному в искусстве Листа было связано с поисками выхода за установленные пределы имманентного в музыке». Способами обретения трансцендентного в творчестве композитора, по мнению исследователя, явились «прорывы за пределы» «одного вида искусства», жанра, традиционного круга тематики, темброво-исполнительских возможностей фортепиано, соотносимого с оркестром [см. об этом более подробно: 10, 98]. Особое место в данном перечне принадлежит виртуозно-исполнительскому фактору, становящемуся в романтическом искусстве символом «абсолютного мастерства» и свободы творчества Художника. В этом плане феномен «виртуозности» и «виртуоза» в их романтическом понимании демонстрирует непосредственную взаимосвязь с понятием «трансцендентного».

В большинстве энциклопедических изданий термины «виртуоз», «виртуозность» чаще всего ассоциируются с «высоким отточенным мастерством», с «совершенной степенью музыкального исполнения как в смысле техническом, так и художественном» [5]. Корневая и этимологическая основа данных слов восходит к латинскому «Virtus», буквально обозначающему «силу, доблесть, талант». Это понятие занимало существенное место как в мифологической традиции, так и в этике Древнего Рима. «Виртус (Virtus) в римской мифологии - персонификация мужественности как главной добродетели римского 
народа» [6, 237]. В последующие периоды истории корневая основа данного слова и сопряженная с ним этимология утвердились в западноевропейской духовно-эстетической, теоретической, а также и в художественно-исполнительской практике.

Эпоха романтизма, как указывалось выше, стала одной из кульминационных точек в развитии феномена виртуозности, поскольку именно в XIX ст., согласно А. Михайлову, выкристаллизовалось «самосознание музыки как содержательного и смыслового искусства». Показательной в этом плане выступает классификация исторических «типов виртуозности», представленная в докторском исследовании Б. Б. Бородина. Эпоха романтизма как одна из наивысших точек в развитии данного феномена, согласно позиции исследователя, порождает особый «трансцендентный тип виртуозности», характеризующийся стремлением к выходу за пределы возможностей конкретного инструмента и отдельного вида искусства» $[4,27]$. Осуществляемый «словно «поверх барьеров» установленных природе человека» $[4,26]$, романтический тип виртуозности, по мнению М. В. Гоголавшвили, непосредственно связан с идеей трансцендентности, рассматриваемой в рамках музыкального романтизма на уровне «...сознательного выхода за пределы музыкального (и не только) искусства в сферы, которые «больше искусства» - мир идей, философских абстракций, религиозного опыта» [9].

Для этюда в музыкальном творчестве и исполнительстве также весьма показательны вышеизложенные грани и смыслы. Семантика музыкального этюда на разных стадиях его существования и развития соотносима не только с совершенствованием исполнительских навыков, но и с творческой деятельностью. Имея точки соприкосновения с различными типологиями, этюд во всем разнообразии его проявлений (инструктивный, «характеристический», «концертно-художественный») фактически демонстрировал способность «вхождения» и «освоения» различных жанровых моделей и сопутствующих им музыкально-выразительных типологических качеств. Решающую роль в формировании этюда как жанра сыграла эпоха романтизма, в рамках которой этюд в его лучших образцах демонстрирует как никакой иной жанр реальную способность творческого освоения не только технико-исполнительских приемов, но и жанрово-стилевого языка различных эпох и их репрезентантов. Обозначенные качества этюда А. Генкин обобщает и на уровне представления о нем как о «носителе особого вида эстетической (музыкально-игровой) деятельности», 
и как о «способе преподнесения интрамузыкального и интрапианистического начал» и, наконец, как о произведении музыкального искусства, потенциально открытом любому типу содержания» [8, 137].

Сказанное соотносимо и с циклом «12 трансцендентных этюдов» Ф. Листа, соотносимых с поэмными композициями. Названный цикл известен в трех редакциях. Первая (1826) носила название «Этюды для фортепиано в виде двенадцати упражнений» и знаменовала начало творческого пути будущего виртуоза. Вторая версия цикла (1838) - «12 больших этюдов» - кардинально отличалась от первой своим невероятным виртуозным блеском. По мнению Ф. Бузони, в этих этюдах Ф. Лист «...как будто без всякой подготовки и постепенности перескочил через все действительные и предполагаемые возможности рояля, и никогда уже больше нога его не брала разгона для такого огромного прыжка» $[15,10]$. Наконец, в третьей редакции (1851) этюды получили свой нынешний вид и окончательное наименование - «Трансцендентные этюды». Данный вариант, в отличие от предыдущего, при всем блеске фортепианного технического мастерства, все же нацелен на большую экономию средств. Последняя версия цикла (близкая предыдущей) в полной мере отразила листовское понимание «трансцендентного» в пианистическом искусстве. Последнее подразумевало «не узко техническое совершенство, не владение высшей степенью трудности, а виртуозность в подлинном смысле этого слова - умение исполнить музыкальное произведение во всем его блеске и свежести, умение художественно мыслить за фортепиано, заставить технику, как помощницу поэтической идеи, «идти на поводу» у последней, - то есть высшее исполнительское мастерство» $[15,16]$, которое, добавим, и становится средством «прорыва» в сферу трансцендентного в его высоком понимании, составляющем духовный базис искусства романтизма (см. выше).

Цикл этюдов Ф. Листа в полной мере демонстрирует не только высочайший уровень пианистического мастерства, но и типологический потенциал жанра этюда как такового (см. выше). Образносмысловая сторона данного сочинения, в соответствии с программными определениями, охватывает тот круг тематики, который можно считать показательным не только для творчества Ф. Листа, но и для всей романтической музыкально-исторической традиции в целом. Работая в этом жанре, композитор подытожил не только собственные результаты деятельности предшествующего периода, но и многое из этюдного наследия предшествующих авторов, так или ина- 
че оказавших воздействие на его творчество. «Остов» драматургии цикла составили наиболее емкие и характерные образно-смысловые «коды» романтического искусства, что и позволило Ф. Листу довести жанр этюда до творческо-исполнительской вершины его развития, определенной автором как «трансцендентный этюд». Героико-драматические образы в их романтическом понимании («Мазепа», «Героика») соседствуют в цикле с мистико-фантастическими («Видение», «Блуждающие огни», «Дикая охота»), молитвенно-медитативными («Вечерние гармонии»), а также дополняются пасторальной образностью, символизирующей гармонию человеческого и природного начал («Пейзаж»).

Ф. Лист создал эталон принципиально нового концертного этюда, обогащенного фактурным разнообразием и высокохудожественной образностью, дополняемой также семантикой широчайшего жанрового спектра, охватываемого в данном цикле. Опираясь на типологию этюда (см. выше), композитор апеллирует к приему «обобщения через жанр», который в художественном тексте романтиков функционирует как программно осмысленный компонент организации смыслового ряда. В «Трансцендентных этюдах» главный жанровый «акцент» приходится на вальс, используемый во многих пьесах цикла. Помимо вальса, своеобразными лейтжанрами опуса становятся марш, песня, хорал и др. Существенное место занимают также типологические признаки токкаты и каприччио, придающие концертный блеск этюдам и способствующие гибкости метроритмической и темповой организации составляющих данного цикла. Одновременно отметим значительную роль жанровых признаков баллады и поэмы, показательных практически для каждого из этюдов. Таким образом, анализируемый цикл этюдов Ф. Листа демонстрирует широкий спектр интерпретации автором принципа «трансцендентного», проявляемый как на уровне предельно возросшего технико-исполнительского мастерства, так и на уровне расширения образно-смыслового диапазона жанра, подкрепляемого столь показательным для этюда виртуозным творческим «вхождением» и воспроизведением иных типологий.

Обозначенные качества листовского цикла нашли претворение и в иных композиторских школах, в частности в русской. Наиболее последовательными адептами стилевых и исполнительских новаций Ф. Листа по праву считаются М. Балакирев и С. М. Ляпунов. Характеризуя развитие русской фортепианной школы второй половины 
XIX - начала XX ст., Б. В. Асафьев особо выделял в ней «балакиревско-ляпуновский пианизм». Обобщая поэтику фортепианного наследия С. М. Ляпунова, в частности, его «12 трансцендентных этюдов», исследователь отмечает, что фактура его сочинений «...пышнее и импозантнее, чем у Балакирева. Влияние Листа проявляется в ней еще интенсивнее. Характер фортепианной музыки Ляпунова в большей мере концертно-виртуозный, чем салонный» [1, 234, 232]. Подобного рода выводы, равно как и фортепианный стиль С. М. Ляпунова, во многом определены и творческой биографией композитора. Существенное влияние на становление его пианизма, по свидетельствам биографов, оказали музыканты «листовского круга» - К. Клиндворт и П. А. Пабст.

Выводы. Обозначенные качества фортепианного творчества С. М. Ляпунова наиболее полно сконцентрированы в его «12 этюдах», которые были задуманы как своеобразное продолжение аналогичного листовского цикла. При этом отметим, что если последний был ориентирован на бемольную сферу тональностей, то сочинение С. М. Ляпунова апеллирует к диезному кругу тональностей. Обговаривая данный замысел в дружеском кругу, композитор, тем не менее, из соображений скромности не решился декларировать данную идею в печатном издании своих этюдов и потому ограничился лаконичным посвящением своего цикла «Памяти Ф. Листа». О данном замысле также напоминает и финальный 12-й этюд, носящий заголовок «Элегия памяти Франца Листа».

Цикл, с одной стороны, продолжает и развивает идею «трансцендентного этюда», достигшего апогея в наследии великого пианиста-романтика. Все этюды С. М. Ляпунова представляют собой развернутые программные композиции поэмного типа. Помимо этого третьему («Трезвон») и четвертому («Терек») этюдам предпосланы также дополнительные программные пояснения. Практически все этюды цикла характеризуются охватом широкого диапазона, «оркестральной» трактовкой фортепиано, тонким применением регистровых тембров, демонстрирующими в совокупности «сверхвозможности» инструмента, показательные именно для его романтической трактовки. Очевидны и образно-смысловые аллюзии между циклами названных авторов. С. М. Ляпунов, подобно Ф. Листу, также апеллирует в своих этюдах к мистико-фантастической тематике («Хоровод призраков», «Хоровод сильфов»), к пейзажно-пасторальной лирике («Летняя ночь», «Идиллия»), драматическим темам («Буря»). 
По мысли Б. Печерского, «музыка - одушевленный вариант всех остальных искусств, вместе взятых, и - воодушевленный перспективой бесконечного совершенства». «Трансцендентные этюды» Ф. Листа и их аналог, представленный циклом «12 этюдов» С. М. Ляпунова, в полной мере подтверждают данное качество, весьма показательное именно для культурно-эстетических и философских установок романтизма. Трансцендентность названных сочинений оказывается сродни обозначенной выше «перспективе бесконечного совершенства», равно как и кантовским «основоположениям трансцендентного», что находит отражение не только в предельно возросшем техническо-исполнительском мастерстве «композитора-виртуоза», необходимом для интерпретации подобных сочинений, но и в максимальном расширении типологической и образно-смысловой стороны этюда, охватывающей отныне как инструктивную риторико-исполнительскую сторону данного жанра, так и образно-смысловые «коды» романтического искусства в целом.

\section{СПИСОК ЛИТЕРАТУРЫ}

1. Асафьев Б. В. Русская музыка. ХІХ и начало XX века. - 2-е изд. / Б. В. Асафьев. - Л.: Музыка, 1979. - 344 с.

2. Бахтизина Д. И. Истинность музыки (Онтологический аспект) : дис. ... канд. философ. наук : 09.00.01 - онтология и теория познания / Д. И. Бахтизина. - Сибай, 2006. - Режим доступа : www.dslib.net/ontologia/istinnostmuzyki.html

3. Бердяев Н. А. Философия свободы. Смысл творчества / Н. А. Бердяев. - М.: Правда, 1989. - 608 с.

4. Бородин Б. Б. Феномен фортепианной транскрипции: опыт комплексного исследования : автореф. дис. ... д-ра искусствоведения : 17.00.02 - Музыкальное искусство. - М., 2006. - 46 с.

5. Виртуозность. - Интернет-ресурс. - Режим доступа : dic.academic.ru/ dic.usf/brokgauz_efron/22467/Виртуозность

6. Виртус // Мифы народов мира. Энциклопедия: в 2 томах / гл. ред. С. А. Токарев. - М.: Рос. Энциклопедия, 1994. - Т. 1. А - К. - С. 237.

7. Волков В. В. Филология в системе современного гуманитарного знания: учебное пособие / В. В. Волков. - М.: ФЛИНТА, 2014. - 222 с.

8. Генкин А. А. Эстетический смысл этюдов Карла Черни как фактор овладения профессией пианиста-исполнителя / А. А. Генкин // Культура народов Причерноморья. - 2012. - № 236. - С. 136-138.

9. Гоголашвили М. В. Проявление принципа виртуозности в жанре этюда, его трансформация в музыкальном искусстве XIX-XXI веков / М. В. Го- 
голашвили. - Интернет-ресурс. - Режим доступа : www.rusnauka.com/4 SND_2014/MusicaAndLife/1_157174.doc.htm

10. Калинин С. Трансцендентное в философии XVIII - первой половины XIX века в творчестве Листа / С. Калинин // Ференц Лист и проблемы синтеза искусств: Сборник научных трудов / сост. Г. И. Ганзбург. - Харьков: Издательская группа «РА - Каравелла», 2002. - С. 92-100.

11. Кант И. Сочинения: в 6 томах / под общ. ред. В. Ф. Асмуса, А. В. Гулыги, Т. И. Ойзермана / И. Кант. - М.: Мысль, 1964. - Т. 3. - 799 с.

12. Лаврухина И. М. Идея трансцендентного: концептуальные версии в культуре: автореф. дис. ... д-ра философ. наук : 09.00.13 - религиоведение, философская антропология, философия культуры / И. М. Лаврухина. Ростов-на-Дону, 2008. - 42 с.

13. Литературные манифесты западноевропейских романтиков / под ред. А. С. Дмитриева. - М.: Издательство Московского университета, 1980. $639 \mathrm{c}$.

14. Медушевский В. В. Онтологическая теория коммуникации как объяснительный принцип в музыкознании / В. В. Медушевский // Музыкальная академия. -2010 . - № 3. - С. 55-68.

15. Мильштейн Я. Этюды Ф. Листа / Я. Мильштейн. - М.: Государственное музыкальное издательство, 1961. - 84 с.

16. Панкова Е. А. «Новое средневековье» в эстетике немецкого романтизма / Е. А. Панкова // Вестник ВГУ. Серия: Филология. Журналистика. 2005. - № 2. - С. 80-86.

17. Содейка Т. А. Трансцендентный / Т. А. Содейка // Философский словарь / под ред. И. Т. Фролова. - 7-е изд., перераб. и доп. - М.: Республика, 2001. - С. 579.

18. Шелли П. Б. Письма. Статьи. Фрагменты / П. Б. Шелли. - М.: Наука, 1972. $-537 \mathrm{c}$.

\section{REFERENCES}

1. Asafev, B. (1979). Russkaya muzyika. XIX i nachalo XX veka. L.: Muzyika [in Russian].

2. Bahtizina, D. (2006). Istinnost muzyiki (Ontologicheskiy aspekt). - Diss. ... kand. filosofskih nauk : 09.00.01 - ontologiya i teoriya poznaniya. - Sibay. URL : www.dslib.net/ontologia/istinnost-muzyki.html [in Russian].

3. Berdyaev N. (1989). Filosofiya svobodyi. Smyisl tvorchestva. M.: «Pravda» [in Russian].

4. Borodin B. (2006). Fenomen fortepiannoy transkriptsii: opyit kompleksnogo issledovaniya. - Avtoref. diss....doktora iskusstvovedeniya : 17.00.02 - Muzyikalnoe iskusstvo. - M. [in Russian].

5. Virtuoznost. URL: dic.academic.ru/dic.usf/brokgauz_efron [in Russian].

6. Virtus (1994) // Mifyi narodov mira. Entsiklopediya: v 2-h tomah / Gl. red. S. A. Tokarev. M.: Ros. Entsiklopediya. T. 1. A-K. [in Russian]. 
7. Volkov, V. (2014). Filologiya v sisteme sovremennogo gumanitarnogo znaniya: Uchebnoe posobie. M.: FLINTA [in Russian].

8. Genkin, A. (2012). Esteticheskiy smyisl etyudov Karla Cherni kak faktor ovladeniya professiey pianista-ispolnitelya // Kultura narodov Prichernomorya. \# 236. [in Russian].

9. Gogolashvili, M. Proyavlenie printsipa virtuoznosti v zhanre etyuda, ego transformatsiya v muzyikalnom iskusstve XIH-XXI vekov. URL : www.rusnauka. com/4_SND_2014/MusicaAndLife/1_157174.doc.htm [in Russian].

10. Kalinin, S. (2002). Transtsendentnoe v filosofii XVIII - pervoy polovinyi XIX vekov v tvorchestve Lista // Ferents List i problemyi sinteza iskusstv: Sbornik nauchnyih trudov / Sost. G. I. Ganzburg. Harkov: Izdatelskaya gruppa «RA - Karavella» [in Russian].

11. Kant, I. (1964). Sochineniya: v 6-ti tomah / Pod obsch. red. V. Asmusa, A. V. Gulyigi, T. I. Oyzermana. M.: Myisl. T. 3 [in Russian].

12. Lavruhina, I. (2008). Ideya transtsendentnogo: kontseptualnyie versii v kulture. - Avtoref. diss. ... doktora filosofskih nauk : 09.00.13 - religiovedenie, filosofskaya antropologiya, filosofiya kulturyi. Rostov-na-Donu [in Russian].

13. Literaturnyie manifestyi zapadnoevropeyskih romantikov (1980) / Pod red. A. Dmitrieva. M.: Izdatelstvo Moskovskogo universiteta [in Russian].

14. Medushevskiy, V. (2010). Ontologicheskaya teoriya kommunikatsii kak ob'yasnitelnyiy printsip v muzyikoznanii // Muzyikalnaya akademiya. \# 3 [in Russian].

15. Milshteyn, Y. (1961) Etyudyi F. Lista. M.: Gosudarstvennoe muzyikalnoe izdatelstvo [in Russian].

16. Pankova, E. (2005). «Novoe srednevekove» v estetike nemetskogo romantizma / // Vestnik VGU. Seriya: Filologiya. Zhurnalistika. \# 2 [in Russian].

17. Sodeyka, T. (2001). Transtsendentnyiy // Filosofskiy slovar / Pod red. I. T. Frolova. M.: Respublika [in Russian].

18. Shelli, P. (1972). Pisma. Stati. Fragmentyi. M.: Nauka [in Russian].

Стаття надійшла до редакції 07.06.2016

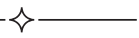

